\title{
Paradoxical role of hepatocyte growth factor in ischemic stroke: stroke risk/stroke recovery
}

\author{
Ibraheim Al-Ahmar ${ }^{1}$, Noha Mohamed ${ }^{2}$ and Hosna Elshony ${ }^{1 *}$ (i)
}

\begin{abstract}
Background: Hepatocyte growth factor (HGF) has an obvious pathological role in atherosclerosis and plaque instability leading to an acute ischemic stroke; however, its beneficial role in stroke recovery is still restricted to experimental studies. The aim of the current study was to investigate the association between HGF and carotid atherosclerosis and evaluate its value as a prognostic marker of ischemic stroke and its role in stroke recovery.

Results: This case-control study was done on 100 patients with first time anterior circulation ischemic stroke, subjected to clinical and laboratory evaluation of atherosclerosis risk factors. Brain imaging, cardiac work-up and ultrasonographic assessment of carotid atherosclerosis (using intimal medial thickness and plaque score) were all done. Clinical evaluation of initial stroke severity, using National Institutes of Health Stroke Scale (NIHSS), and stroke outcome after 3 m, using Modified Rankin Scale (MRS), was performed. Measurement of HGF serum concentration was done to all stroke patients within $24 \mathrm{~h}$ of stroke onset and compared to results of 100 matched healthy subjects aged more than 50 years. HGF was significantly higher in stroke patients than healthy controls and in atherothrombotic than cardioembolic stroke group and its level was significantly correlated with atherosclerosis risk factors, degree of carotid atherosclerosis and better stroke outcome; however, it was not significantly correlated with initial stroke severity.

Conclusion: HGF is strongly associated with carotid atherosclerosis and other atherosclerosis risk factors and subsequent atherothrombotic stroke. Also, it can be used as a good prognostic marker in atherothrombotic stroke suggesting its role in stroke recovery but more studies are needed to explore this beneficial role as well as its therapeutic potentials in ischemic stroke patients.
\end{abstract}

Keywords: Hepatocyte growth factor, Ischemic stroke, Atherosclerosis, Prognosis

\section{Background}

Hepatocyte growth factor (HGF), initially described as a mitogen for hepatocytes, is a potent angiogenic factor and endothelium-specific growth factor that affects a wide range of tissues $[1,2]$. Previous data in humans have demonstrated expression of HGF and its receptor c-Met in atherosclerotic plaques [3]. So, it is hypothesized that HGF may play a role in the natural history of atherosclerosis and hence the pathogenesis of cerebrovascular

\footnotetext{
*Correspondence: hosna.saad28@gmail.com

1 Department of Neuropsychiatry, Faculty of Medicine, Menoufiya

University, Shebin El-Kom 24211, Egypt

Full list of author information is available at the end of the article
}

disease, including ischemic stroke $[4,5]$. High HGF levels, within atherosclerotic plaques, may lead to plaque neovascularization $[3,6]$, which in turn, facilitates infiltration of leukocytes and inflammatory stimuli. Subsequently these changes further enhance angiogenesis in atherosclerotic lesions with further plaque instability and plaque rupture leading to an acute ischemic stroke $[7,8]$. It is unclear whether high HGF levels are a risk factor for ischemic stroke or a result of it, and whether HGF is an independent risk factor for stroke or merely a marker for other cardiovascular diseases (CVD) risk factors.

On the other hand, HGF was described as a neuroprotector and angiogenesis promoter after cerebrovascular accidents [9]. It was found that HGF levels in the 
acute stroke phase correlate closely with clinical recovery in the post-acute stroke phase, by inducing long-term neuroprotection lasting beyond the discontinuation of treatment, translating into enhanced motor coordination recovery suggesting that HGF induces favorable responses in the brain tissue that facilitate brain remodeling, and these unique features make it a promising agent for stroke treatment $[10,11]$.

To address these two contradictory issues, we conducted the present study to investigate the correlation between HGF and acute ischemic stroke, stroke severity, stroke subtype (atherothrombotic versus cardioembolic), carotid atherosclerosis and other atherosclerotic risk factors, also to evaluate its prognostic value and role in stroke recovery, opening road for exploring its therapeutic potentials in acute stroke.

\section{Methods}

This study was conducted on 100 first time anterior circulation acute ischemic stroke patients, within $24 \mathrm{~h}$ of stroke onset, 49 males and 51 females, aged more than 50 years, enrolled from our hospital between May 2017 and May 2018. Patients were matched with 100 healthy subjects (who do not have risk factors like diabetes, hypertension, smoking, dyslipidemia) aged more than 50 years recruited form outpatient clinics.

All 100 stroke patients included in this study were subjected to thorough history taking, complete general and neurological examinations, body mass index (BMI) calculation $\left[\mathrm{BMI}=\right.$ weight $(\mathrm{kg}) /$ height $\left.\left(\mathrm{m}^{2}\right)\right]$ and obesity was defined as: BMI $>25 \mathrm{~kg} / \mathrm{m}^{2}$ [12], assessment of stroke severity using National Institutes of Health Stroke Scale (NIHSS), and routine laboratory measurements including fasting blood sugar, fasting lipid profile, serum creatinine, liver function tests and cardiac enzymes (CK-MB, Troponin I).

High-resolution B-mode ultrasound color Doppler, and pulse Doppler ultrasonography of both carotid arteries were performed to all patients using (SONOS 5500; Hewlett Packard, USA) with linear transducer $10 \mathrm{MHz}$ array probe with measuring of intima-media thickness (IMT) and plaque score (PS). Carotid IMT was measured as the distance from the leading edge of the first echogenic line (lumen-intima interface) to the leading edge of the second echogenic line (media-adventitia interface). Mean (IMT) is calculated by measuring the mean of the IMT of right and left common carotid artery (CCA). Carotid atherosclerosis was defined as carotid intimamedia thickness IMT $>0.8 \mathrm{~mm}$ [13]. Plaque was defined as: the presence of wall thickness of at least $50 \%$ greater than the thickness of the surrounding wall [12], or a protrusion into the lumen. Carotid atherosclerosis was classified as either mild [IMT $0.9-1 \mathrm{~mm}$ ], moderate (IMT
1.1-1.9 $\mathrm{mm}$ ) and severe (IMT $\geq 2 \mathrm{~mm}$ ) [14]. Plaque score (PS) was calculated as the sum of the thickness of all the plaques in both carotid arteries [5, 15]. Carotid plaque burden was classified according to plaque score (PS) into normal (score 0 ), mild (score 1-5), moderate (score 5.110), and severe (score over 10) [16]. Three months after the onset of stroke, the functional outcome of stroke was assessed by Modified Rankin Scale (MRS) done by senior neurologist in the outpatient clinic follow-up visit. Brain imaging [either computed tomography $(\mathrm{CT})$ or magnetic resonance imaging (MRI)], electrocardiography (ECG), Holter and echocardiograph examination were performed to all patients included in this study.

Measurement of serum HGF concentrations done to all stroke patients and control group. Samples were collected within $24 \mathrm{~h}$ from stroke onset. HGF concentration in the serum was determined using an enzyme-linked immunosorbent assay kit for human HGF (Human HGF instant ELISA BMS2069INST, Affymetrix eBioscience, Vienna, Austria). The interassay and intra-assay coefficients for this assay were $8.3 \%$ and $7.6 \%$, respectively. The reference range reported by the manufacturer was $<0.390 \mathrm{ng} / \mathrm{ml}$.

Depending on results of brain imaging, cardiac workup and carotid ultrasound, stroke patients were divided into two groups: 50 patients with carotid atherosclerosis without cardiac source (atherothrombotic) and 50 patients with cardiac source of the stroke (atrial fibrillation; AF) without carotid atherosclerosis (cardioembolic).

Patients were excluded if they have previous stroke (hemorrhagic or ischemic), transient ischemic attack (TIA), brain tumor, demyelinating disease or CNS infection, chronic liver or renal diseases. Posterior circulation strokes were also excluded as usefulness of duplex ultrasonography (DUS) for screening of extracranial vertebral artery stenosis or visualization of atherosclerosis is limited [17].

The study was performed in accordance with the Declaration of Helsinki and approved by the local ethical committee and informed verbal consent was obtained from all subjects before the study was commenced after fully explaining the study and its aims to them.

\section{Statistical analysis}

Statistical analysis was conducted by Statistical package of Social Science (SPSS) version 20 (IBM Corp. Released 2012. IBM SPSS Statistics for Windows, Version 21.0. Armonk, NY: IBM Corp.). Quantitative data were expressed as mean and standard deviations $(X \pm \mathrm{SD})$ and analyzed applying Student $t$-test. The Mann-Whitney $U$ and Kruskal-Wallis $H$ test were used to allow the comparison of two or more independent groups. $P<0.05$ was determined as statistically significant, whereas $P$ value $<0.001$ was considered to be highly statistically 
significant, on the other hand $P$ value $>0.05$ was considered statistically not significant. Statistical correlations using Spearman's correlation coefficient, ( $\rho$, also signified by rs) used to measure the strength and direction of association between ranked variables.

\section{Results}

The clinical parameters of all patients and controls are presented in Table 1, which shows no difference in age and sex distribution among cases and control groups.

On comparing between atherothrombotic and cardioembolic stroke groups, all vascular risk factors were distributed more in atherothrombotic than the cardioembolic group (Table 2), also degree of carotid atherosclerosis measures by IMT and carotid plaque burden measured by PS were statistically significantly higher in the atherothrombotic group (Tables 3,4). There was no difference between both groups in the initial stroke severity assessed by NIHSS (Table 5), however the stroke outcome after 3 months measures by MRS was better in atherothrombotic group than cardioembolic with statistically significant difference (Table 6).

The mean serum concentration of HGF in stroke patients group was statistically significant higher than that of the control group (Table 7) and in the atherothrombotic stroke group than cardioembolic ones
(Table 8), and in those with vascular risk factors for atherosclerosis (smoking, obesity, dyslipidemia, DM and hypertension) than those without (Table 9). Also it was directly related to the increase in age of stroke patients in a statistically significant way (Table 10) and the degree of atherosclerosis either by IMT or the carotid plaque score burden (Tables 11,12), but not with sex or initial stroke severity assessed by (NIHSS) (Table 13).

On the other hand, we find a significant correlation between higher HGF levels and lesser functional disability after 3-month measures by MRS indicating better prognosis (Tables 14, 15).

\section{Discussion}

In the current study, HGF concentration was significantly higher in stroke patients than control and in atherothrombotic stroke than cardioembolic ones. These results were matched with many studies [1821 , who reported an increase of HGF in the very early stage of ischemic stroke and it decreases as the disease evolves, suggesting that thrombus formation abated. So they suggested that circulating HGF is a reliable early marker of cerebral infarction, its assay may be useful for diagnosing cerebral thrombosis. HGF might be released from the vessel wall by unknown mechanisms related to endothelial damage mediated by thrombus formation

Table 1 Age and sex distribution among cases and control groups

\begin{tabular}{|c|c|c|c|c|c|c|}
\hline & \multicolumn{3}{|c|}{ The studied groups } & & \multirow[t]{2}{*}{ Test } & \multirow[t]{2}{*}{$P$ value } \\
\hline & & & Control $N=100$ & & & \\
\hline \multicolumn{7}{|l|}{ Age } \\
\hline$X \pm S D$ & & & $70.30 \pm 9.17$ & & 0.85 & 0.38 \\
\hline \multirow[t]{2}{*}{ Range } & & & $51-85$ & & & \\
\hline & No & $\%$ & No & $\%$ & $\mathrm{X}^{2}$ & \\
\hline \multicolumn{7}{|l|}{ Sex } \\
\hline Male & 49 & 49 & 54 & 54 & 0.5 & 0.48 \\
\hline Female & 51 & 51 & 46 & 46 & & \\
\hline
\end{tabular}

$X$ mean, $S D$ standard deviation, $\mathrm{X}^{2}$ Chi-square test

Table 2 Vascular risk factors for atherosclerosis among patients group

\begin{tabular}{|c|c|c|c|c|c|c|}
\hline & \multicolumn{6}{|c|}{ The patient group (100 stroke patients) } \\
\hline & \multicolumn{2}{|c|}{ Carotid atherosclerosis $N=50$} & \multicolumn{2}{|c|}{ Cardioembolic $N=50$} & \multicolumn{2}{|c|}{ Total $N=100$} \\
\hline & No & $\%$ & No & $\%$ & No & $\%$ \\
\hline Smoking & 27 & 54 & 5 & 10 & 32 & 32 \\
\hline Obesity & 43 & 86 & 16 & 32 & 59 & 59 \\
\hline DM & 42 & 84 & 11 & 22 & 53 & 53 \\
\hline Dyslipidemia & 37 & 74 & 11 & 22 & 48 & 48 \\
\hline Hypertension & 37 & 74 & 30 & 60 & 67 & 67 \\
\hline
\end{tabular}


Table 3 Carotid intima-media thickness (IMT) among atherosclerotic and cardioembolic groups

\begin{tabular}{|c|c|c|c|c|c|c|c|c|c|}
\hline & \multicolumn{6}{|c|}{ The patient group } & & \multirow[t]{2}{*}{ Test $U$} & \multirow[t]{2}{*}{$P$ value } \\
\hline & \multicolumn{2}{|c|}{$\begin{array}{l}\text { Carotid atherosclerosis } \\
N=50\end{array}$} & \multicolumn{2}{|c|}{ Cardioembolic $N=50$} & & \multirow[t]{2}{*}{ Total $N=100$} & & & \\
\hline \multicolumn{9}{|l|}{ IMT } & \\
\hline$X \pm S D$ & \multicolumn{2}{|c|}{$2.27 \pm 1.26$} & \multicolumn{2}{|c|}{$0.60 \pm 0.14$} & & \multicolumn{2}{|l|}{$1.44 \pm 1.22$} & 8.6 & $<0.001^{*}$ \\
\hline \multirow[t]{2}{*}{ Range } & \multicolumn{2}{|l|}{$0.90-5$} & \multicolumn{2}{|c|}{$0.3-0.80$} & & \multicolumn{2}{|l|}{$0.3-5$} & & \\
\hline & & No & $\%$ & No & $\%$ & & & $x^{2}$ & \\
\hline \multicolumn{10}{|c|}{ Atherosclerosis severity } \\
\hline \multicolumn{2}{|c|}{$\mathrm{No}(\mathrm{IMT} \leq 0.8 \mathrm{~mm})$} & 0 & 0 & 50 & 100 & 50 & 50 & 100 & $<0.001^{*}$ \\
\hline \multicolumn{2}{|c|}{ Mild (IMT 0.9-1 mm) } & 11 & 22 & 0 & 0 & 11 & 11 & & \\
\hline \multicolumn{2}{|c|}{ Moderate (IMT 1.1-1.9 mm) } & 17 & 34 & 0 & 0 & 17 & 17 & & \\
\hline \multicolumn{2}{|c|}{ Severe (IMT $\geq 2 \mathrm{~mm}$ ) } & 22 & 44 & 0 & 0 & 22 & 22 & & \\
\hline
\end{tabular}

$X$ mean, $S D$ standard deviation, $X^{2}$ Chi-square test, $U$ Mann-Whitney $U$, *highly significant, $I M T$ intimal medial thickness

Table 4 Carotid plaque burden among atherosclerotic and cardioembolic groups

\begin{tabular}{|c|c|c|c|c|c|c|c|c|}
\hline & \multicolumn{5}{|c|}{ The patient group } & & \multirow[t]{2}{*}{ Test $U$} & \multirow[t]{2}{*}{$P$ value } \\
\hline & \multicolumn{2}{|c|}{$\begin{array}{l}\text { Carotid atherosclerosis } \\
N=50\end{array}$} & \multicolumn{2}{|c|}{ Cardioembolic $N=50$} & \multirow[t]{2}{*}{ Total $N=100$} & & & \\
\hline \multicolumn{8}{|c|}{ Number of plaques } & \\
\hline$X \pm S D$ & \multicolumn{2}{|l|}{$7.16 \pm 5.23$} & \multicolumn{2}{|c|}{$0.0 \pm 0.0$} & \multicolumn{2}{|l|}{$3.58 \pm 5.15$} & \multirow[t]{2}{*}{8.4} & $<0.001$ \\
\hline \multirow[t]{2}{*}{ Range } & $0-17$ & & \multicolumn{2}{|l|}{$0-0$} & \multicolumn{2}{|l|}{$0-17$} & & \\
\hline & No & $\%$ & No & $\%$ & & & $x^{2}$ & \\
\hline \multicolumn{9}{|l|}{ Plaque burden } \\
\hline No plaques & 6 & 12.0 & 50 & 100 & 56 & 56 & \multirow[t]{4}{*}{78.6} & \multirow[t]{4}{*}{$<0.001$} \\
\hline Mild & 14 & 28.0 & 0 & 0 & 14 & 14 & & \\
\hline Moderate & 10 & 20.0 & 0 & 0 & 10 & 10 & & \\
\hline Severe & 20 & 40.0 & 0 & 0 & 20 & 20 & & \\
\hline
\end{tabular}

$X$ mean, $S D$ standard deviation, $X^{2}$ Chi-square test, $U$ Mann-Whitney $U$, *highly significant

Table 5 National Institutes of Health Stroke Scale (NIHSS) among patients group

\begin{tabular}{|c|c|c|c|c|c|c|c|c|}
\hline & \multicolumn{5}{|c|}{ The patient group (100 stroke patients) } & & \multirow[t]{2}{*}{ Test } & \multirow[t]{2}{*}{$P$ value } \\
\hline & $\begin{array}{l}\text { Carotid atherosclerosis } \\
N=50\end{array}$ & & Cardioembolic $N=50$ & & Total $N=100$ & & & \\
\hline \multicolumn{9}{|l|}{ NIHSS } \\
\hline$X \pm S D$ & $12.64 \pm 9.89$ & & $13.88 \pm 8.61$ & & $13.26 \pm 9.24$ & & 0.69 & 0.49 \\
\hline \multirow[t]{2}{*}{ Range } & $1-40$ & & $1-35$ & & $1-40$ & & & \\
\hline & No & $\%$ & No & $\%$ & & & $x^{2}$ & \\
\hline \multicolumn{9}{|l|}{ NIHSS } \\
\hline Minor impairment & 15 & 30 & 11 & 22 & 26 & 26 & 2.10 & 0.55 \\
\hline Moderate & 13 & 26 & 13 & 26 & 26 & 26 & & \\
\hline Moderate-to-severe & 11 & 22 & 17 & 34 & 28 & 28 & & \\
\hline Severe impairment & 11 & 22 & 9 & 18 & 20 & 20 & & \\
\hline
\end{tabular}

$X$ mean, $S D$ standard deviation, $X^{2}$ Chi-square test 
Table 6 Modified Rankin Scale (MRS) among patients group

\begin{tabular}{|c|c|c|c|c|c|c|c|c|}
\hline & \multicolumn{6}{|c|}{ The patient group (100 stroke patients) } & \multirow{3}{*}{$\begin{array}{l}\text { Test } \\
\mathrm{X}^{2}\end{array}$} & \multirow[t]{3}{*}{$P$ value } \\
\hline & \multicolumn{2}{|c|}{ Carotid atherosclerosis $N=50$} & \multicolumn{2}{|c|}{ Cardioembolic $N=\mathbf{5 0}$} & \multicolumn{2}{|c|}{ Total $N=100$} & & \\
\hline & No & $\%$ & No & $\%$ & & & & \\
\hline \multicolumn{9}{|c|}{ MRS } \\
\hline 0 & 5 & 10 & 0 & 0 & 5 & 5 & 77.2 & $<0.001^{*}$ \\
\hline 1 & 10 & 20 & 2 & 4 & 12 & 12 & & \\
\hline 2 & 12 & 24 & 1 & 2 & 13 & 13 & & \\
\hline 3 & 8 & 16 & 3 & 6 & 11 & 11 & & \\
\hline 4 & 15 & 30 & 1 & 2 & 16 & 16 & & \\
\hline 5 & 0 & 0 & 39 & 78 & 39 & 39 & & \\
\hline 6 & 0 & 0 & 4 & 8 & 4 & 4 & & \\
\hline
\end{tabular}

$X^{2}$ Chi-square test, MRS Modified Rankin Scale, *highly significant

Table 7 HGF concentration in patients and control groups

\begin{tabular}{lllll}
\hline & \multicolumn{2}{l}{ The studied groups } & U test & $P$ value \\
\cline { 2 - 3 } & Patients $\boldsymbol{N}=\mathbf{1 0 0}$ & Control $\boldsymbol{N = 1 0 0}$ & & \\
\hline HGF Conc. $(\mathrm{ng} / \mathrm{ml})$ & & & \\
$X \pm S D$ & $0.52 \pm 0.18$ & $0.26 \pm 0.08$ & 9.83 & $<0.001^{*}$ \\
Range & $0.15-0.85$ & $0.12-0.39$ & & \\
\hline
\end{tabular}

$X$ mean, $S D$ standard deviation, $U$ Mann-Whitney $U$ test, *highly significant, HGF hepatocyte growth factor

Table 8 HGF concentration in atherothrombotic and cardioembolic groups

\begin{tabular}{lllll}
\hline & \multicolumn{2}{c}{ The patient group } & t-test & $P$ value \\
\cline { 2 - 3 } & $\begin{array}{l}\text { Atherothrombotic } \\
(\boldsymbol{N}=\mathbf{5 0})\end{array}$ & $\begin{array}{l}\text { Cardioembolic } \\
(\boldsymbol{N}=\mathbf{5 0})\end{array}$ & & \\
\hline HGF Conc. $(\mathrm{ng} / \mathrm{ml})$ & & & \\
$X \pm S D$ & $0.62 \pm 0.19$ & $0.41 \pm 0.09$ & 6.88 & $<0.001^{*}$ \\
Range & $0.17-0.85$ & $0.15-0.50$ & & \\
\hline
\end{tabular}

$X$ mean, $S D$ standard deviation, *highly significant, HGF hepatocyte growth factor

[19]. Moreover, in a multi-ethnic study investigating the association of circulating HGF with incident stroke done by Bell and colleagues, they concluded that circulating HGF was positively associated with the incidence of stroke in a diverse, population-based cohort of both sexes from the United States especially with ischemic stroke because there were few hemorrhagic strokes. Their findings support the hypothesis that circulating HGF is a marker of endothelial damage and suggest that HGF may have utility as a prognostic marker of stroke risk [22].

We also found that HFG correlate with degree of carotid atherosclerosis and plaque burden and other
Table 9 The concentration of HGF level in stroke patients with and without vascular risk factors

\begin{tabular}{|c|c|c|c|c|}
\hline \multirow[t]{2}{*}{ Stroke patients $(N=100)$} & \multicolumn{2}{|c|}{$\begin{array}{l}\text { HGF Concentration } \\
(\mathrm{ng} / \mathrm{ml})\end{array}$} & \multirow[t]{2}{*}{$U$ test } & \multirow[t]{2}{*}{$P$ value } \\
\hline & $X \pm \mathrm{SD}$ & Range & & \\
\hline Hypertensive $(N=67)$ & $0.59 \pm 0.14$ & $0.4-0.85$ & 6.24 & $<0.001^{*}$ \\
\hline Non-hypertensive $(N=33)$ & $0.37 \pm 0.17$ & $0.15-0.82$ & & \\
\hline Diabetic $(N=67)$ & $0.62 \pm 0.17$ & $0.23-0.85$ & 6.24 & $<0.001^{*}$ \\
\hline Non-diabetics $(N=33)$ & $0.40 \pm 0.11$ & $0.15-0.54$ & & \\
\hline Smoker $(N=32)$ & $0.72 \pm 0.07$ & $0.60-0.85$ & 7.83 & $<0.001^{*}$ \\
\hline Non-smoker $(N=68)$ & $0.42 \pm 0.12$ & $0.15-0.82$ & & \\
\hline Dyslipidemic $(N=48)$ & $0.61 \pm 0.18$ & $0.43 \pm 0.12$ & 5.07 & $<0.001^{*}$ \\
\hline Non-dyslipidemic $(N=52)$ & $0.17-0.83$ & $0.15-0.85$ & & \\
\hline Obese $(N=59)$ & $0.60 \pm 0.15$ & $0.23-0.83$ & 5.90 & $<0.001^{*}$ \\
\hline Non-obese $(N=41)$ & $0.39 \pm 0.13$ & $0.15-0.82$ & & \\
\hline
\end{tabular}

$X$ mean, $S D$ standard deviation, $U$ Mann-Whitney $U$ test, *highly significant, HGF hepatocyte growth factor

Table 10 HGF concentration in different age groups of stroke patients

\begin{tabular}{|c|c|c|c|c|c|}
\hline & \multicolumn{3}{|c|}{ The patient group (100 stroke patients) } & \multirow[t]{2}{*}{$K$ test } & \multirow[t]{2}{*}{$P$ value } \\
\hline & $\begin{array}{l}\text { Age group } \\
\text { (50- } \\
65 \text { years) }\end{array}$ & $\begin{array}{l}\text { Age group } \\
\text { (66- } \\
80 \text { years) }\end{array}$ & $\begin{array}{l}\text { Age group } \\
\text { ( } \geq 81 \text { years) }\end{array}$ & & \\
\hline \multicolumn{6}{|l|}{ HGF } \\
\hline$X \pm S D$ & $0.33 \pm 0.12$ & $0.50 \pm 0.10$ & $0.74 \pm 0.12$ & 58.5 & $<0.001^{*}$ \\
\hline Range & $0.15-0.50$ & $0.25-70$ & $0.21-0.85$ & & \\
\hline
\end{tabular}

$X$ mean, $S D$ standard deviation, $K$ Kruskal-Wallis test, * highly significant, $H G F$ hepatocyte growth factor 
Table 11 The relation between HGF concentration and the degree of carotid atherosclerosis according to (IMT)

\begin{tabular}{|c|c|c|c|c|c|}
\hline & \multicolumn{4}{|c|}{ Severity of atherosclerosis } & \multirow[t]{2}{*}{$K$ test ( $P$ value) } \\
\hline & No $(\mathrm{IMT} \leq 0.8 \mathrm{~mm})$ & Mild (IMT 0.9-1 mm) & $\begin{array}{l}\text { Moderate (IMT } \\
1.1-1.9 \mathrm{~mm})\end{array}$ & Severe $(\mathrm{IMT} \geq \mathbf{2} \mathrm{mm})$ & \\
\hline \multicolumn{6}{|c|}{ HGFconc. (ng/ml) } \\
\hline$X \pm S D$ & $0.41 \pm 0.09$ & $0.32 \pm 0.15$ & $0.61 \pm 0.04$ & $0.77 \pm 0.04$ & 75.4 \\
\hline Range & $0.15-0.50$ & $0.17-0.59$ & $0.54-0.70$ & $0.71-0.85$ & $(<0.001)^{*}$ \\
\hline
\end{tabular}

$X$ mean, $S D$ standard deviation, $K$ Kruskal-Wallis test, ${ }^{*}$ highly significant, $H G F$ hepatocyte growth factor, IMT intimal medial thickness

Table 12 The relation between HGF concentration and the carotid plaque burden measured by PS

\begin{tabular}{|c|c|c|c|c|c|}
\hline & \multicolumn{4}{|c|}{ Carotid plaque burden (plaque score) (PS) } & \multirow[t]{2}{*}{$K$ test ( $P$ value) } \\
\hline & No plaques (score 0 ) & Mild (score 1-5) & $\begin{array}{l}\text { Moderate (score } \\
5.1 \text { 10) }\end{array}$ & Severe $($ score $>10$ ) & \\
\hline \multicolumn{6}{|c|}{ HGFconc. (ng/ml) } \\
\hline$X \pm S D$ & $0.42 \pm 0.11$ & $0.45 \pm 0.16$ & $0.67 \pm 0.06$ & $0.76 \pm 0.04$ & 63.2 \\
\hline Range & $0.15-70$ & $0.17-0.60$ & $0.61-0.80$ & $0.71-0.85$ & $(<0.001)^{*}$ \\
\hline
\end{tabular}

$X$ mean, $S D$ standard deviation, $K$ Kruskal-Wallis test, *highly significant, $H G F$ hepatocyte growth factor, $P S$ plaque score

Table 13 The relation between HGF concentration and stroke severity assessed by NIHSS

\begin{tabular}{llllll}
\hline & NIHSS & & & \\
\cline { 2 - 6 } & $\begin{array}{l}\text { Minor impairment } \\
\mathbf{N}=\mathbf{2 6}\end{array}$ & $\begin{array}{l}\text { Moderate impairment } \\
\mathbf{N = 2 6}\end{array}$ & $\begin{array}{l}\text { Moderate-to-severe } \\
\text { impairment } \boldsymbol{N}=\mathbf{2 8}\end{array}$ & $\begin{array}{l}\text { Severe impairment } \\
\boldsymbol{N}=\mathbf{2 0}\end{array}$ \\
\hline $\begin{array}{l}\text { HGFconc. }(\mathrm{ng} / \mathrm{ml}) \\
X \pm \text { SD }\end{array}$ & $0.52 \pm 0.19$ & $0.52 \pm 0.16$ & $0.52 \pm 0.18$ & \\
Range & $0.20-0.80$ & $0.17-0.77$ & $0.15-0.83$ & $0.49 \pm 0.18$ & 0.31 \\
\hline
\end{tabular}

$X$ mean, SD standard deviation, K Kruskal-Wallis test, HGF hepatocyte growth factor, NIHSS National Institutes of Health Stroke Scale

Table 14 Relationship between HGF and MRS among patient group

\begin{tabular}{|c|c|c|c|c|}
\hline & \multicolumn{2}{|c|}{$\begin{array}{l}\text { HGF among patient group } \\
N=100\end{array}$} & \multirow[t]{2}{*}{$K$ test } & \multirow[t]{2}{*}{$P$ value } \\
\hline & $X \pm S D$ & Range & & \\
\hline \multicolumn{5}{|c|}{ MRS } \\
\hline 0 & $0.75 \pm 0.04$ & $0.71-0.80$ & 32.5 & $<0.001^{*}$ \\
\hline 1 & $0.63 \pm 0.22$ & $0.17-0.83$ & & \\
\hline 2 & $0.61 \pm 0.26$ & $0.21 \pm 0.85$ & & \\
\hline 3 & $0.56 \pm 0.14$ & $0.21-0.70$ & & \\
\hline 4 & $0.49 \pm 0.14$ & $0.20-0.63$ & & \\
\hline 5 & $0.42 \pm 0.08$ & $0.15-0.50$ & & \\
\hline 6 & $0.40 \pm 0.10$ & $0.25-0.47$ & & \\
\hline
\end{tabular}

$X$ mean, SD standard deviation, MRS Modified Rankin Scale, HGF hepatocyte growth factor, *significant
Table 15 Spearman correlation between HGF and MRS

\begin{tabular}{lll}
\hline & HGF among patient group & \\
\cline { 2 - 3 } & $\boldsymbol{r}$ & $\boldsymbol{P}$ value \\
\hline MRS & -0.52 & $<0.001^{*}$ \\
\hline
\end{tabular}

MRS Modified Rankin Scale, HGF hepatocyte growth factor, *highly significant

atherosclerosis risk factors. These results were matched with the results of previous studies [5, 23, 24].

The role of HGF in the development of carotid atherosclerosis could be proved by the fact that HGF and c-Met are expressed in the atherosclerotic vessel wall and in plaque, but not in normal vessels, as demonstrated by immunohistochemical analysis of human carotid artery sections [3, 25, 26], and that HGF production has been induced, in cultured vascular smooth muscle cells (VSMC), by the proinflammatory mediators interleukin 
1 (IL-1) and tumor necrosis factor alpha (TNF-a), both of which have been found in atherosclerotic plaques and also by low-density lipoprotein (LDL) which is a potent proatherogenic agent [25].

These results imply that serum HGF is a useful marker of carotid atherosclerosis and subsequent liability to cause thrombo-embolic stroke and also to differentiate patients with asymptomatic carotid disease who are at risk of plaque instability, who would benefit more from carotid surgery. Another possible clinical implication of this proatherogenic role of HGF is to question whether the plaque stabilization could be achieved by local therapies [27] delivered through stent- or catheter to eliminate neovascularization in a clinical setting, limiting potential systemic side effects of any therapeutic agents.

On the other end, in our study, we found a significant correlation between high HGF level and better functional outcome assessed by MRS, indicating that HGF could be used as a marker for good prognosis and enhanced recovery after ischemic stroke. Also on the experimental aspect, many studies demonstrated a clear beneficial effect of HGF in ischemic stroke model. HGF and c-Met/ HGF have been reported to be upregulated mainly in the peri-infarct region as long as 28 days after permanent middle cerebral artery occlusion (MCAo), with subsequent increase in microvessels only in the peri-infarct region but not in normal regions [28] and thought to protect neurons or promote angiogenesis after cerebral ischemia.

The role of HGF in recovery of stroke was not only related to the acute stage, but extended to the chronic stage of cerebral infarction, as noted by Shimamura and colleagues, 2006, who demonstrated that HGF gene therapy delayed for as long as 7 days, improved cognitive function from ischemic stroke in the chronic stage of MCAo through reconstitution of the neuronal network [29].

On the contrary, in a study done by Zhu and colleagues, they found that serum HGF levels were higher in more severe stroke at baseline, and elevated HGF levels were probably associated with a 3-month poor prognosis independently of stroke severity among ischemic stroke patients, especially in those without heparin pretreatment [30]. They explained it by its pathological role in plaque progression and instability and greater degree of baseline endothelial dysfunction [20] with subsequent infarct expansion and hemorrhagic transformation [31]. This conclusion was supported by recent study by Zhao and colleagues; they found that soluble interleukin-2 receptors (sIL-2R) and HGF associated with unfavorable outcomes at 3 months after acute ischemic stroke [32].

The improvement in functional recovery in ischemic stroke could be based on two main properties of HGF, neuroprotection and angiogenesis. An ideal therapeutic approach to treat ischemia might have both aspects of enhancement of collateral formation (therapeutic angiogenesis) and prevention of neuronal death. HGF enhances angiogenesis in the ischemic penumbra, improves microcirculation, and inhibits destruction of the blood-brain barrier so reduce cerebral edema [33]. Moreover, HGF exerts a neuroprotective effect after cerebral ischemia by delaying neuronal death and prevention of gliosis through markedly inhibiting the proliferation and migration of astrocytes in the formation process of glial scarring by the sphingosine-1-phosphate pathway, which is closely related to cell proliferation [29, 34]. In conclusion, HGF has therapeutic potential against cerebral ischemia. Binding to the receptor c-Met, downstream signaling pathways are phosphorylated and activated, including the phosphoinositide 3-kinase/protein kinase B (PI3K/Akt), Ras/mitogen-activated protein kinase (MAPK) and signal transducer and activator of transcription (STAT) pathways, and then HGF is capable of regulating angiogenesis, glial scar formation, neurogenesis and anti-apoptosis, protecting the brain from ischemic insults [34].

The implications of this neuroprotective, angiogenic and antigliotic role of HGF were expanded to include both spinal cord and peripheral nerves. In a study done by Kitamura and colleagues, the intrathecal rhHGF preserved the corticospinal fibers and myelinated areas, thereby promoting functional recovery and magnetic resonance imaging showed significant preservation of the intact spinal cord parenchyma [35]. Furthermore, in cellbased therapeutic interventions, HGF was found to promote the survival, neuronal differentiation, and synapse formation of the grafted neural stem cells in the damaged spinal cord contributing to the better functional recovery [36]. As for peripheral nerve injury, its role was proved in animals in a study done by Boldyreva and colleagues who found that treatment by gene therapy with HGF-bearing plasmid (pC4W-hHGF) led to restoration of nerve structure and functional recovery [37].

This obviously well-known profitable role of HGF in neuronal recovery can be clinically implicated as a prognostic tool after stroke and encourage more experiments and clinical trials to study its therapeutic potentials in acute stroke.

\section{Conclusion}

HGF is significantly correlated with the severity of carotid atherosclerosis graded by (IMT and PS) and plaque instability with subsequent liability to cause thrombo-embolic stroke, on the other hand, HGF level correlate well with better functional outcome after stroke. Further studies in larger numbers of patients seem warranted to further 
define the role of increased HGF in the pathogenesis of cerebral infarction, the diagnostic and prognosis power of this new laboratory test; as well as, its therapeutic potentials in acute stroke to enhance recovery.

\begin{abstract}
Abbreviations
HGF: Hepatocyte growth factor; NIHSS: National Institutes of Health Stroke Scale; MRS: Modified Rankin Scale; CVD: Cardiovascular diseases; BMI: Body mass index; IMT: Intima-media thickness; PS: Plaque score; CCA: Common carotid artery; AF: Atrial fibrillation; TIA: Transient ischemic attack; CNS: Central nervous system; DUS: Duplex ultrasonography; SF: Scatter factor; VSMC: Vascular smooth muscle cells; MCAo: Middle cerebral artery occlusion; PI3K/ Akt: Phosphoinositide 3-kinase/protein kinase B; MAPK: Mitogen-activated protein kinase; STAT: Signal transducer and activator of transcription pathway; pC4W-hHGF: Gene therapy with HGF-bearing plasmid.
\end{abstract}

\section{Acknowledgements}

Not applicable.

\section{Authors' contributions}

IA study design, literature review, data acquisition, manuscript preparation. NM study design, data acquisition and analysis, manuscript preparation. H. E. literature search, data acquisition and analysis, manuscript preparation and editing. All authors have read and approved the manuscript.

\section{Funding}

This work has not received any governmental or non-governmental funds.

\section{Availability of data and materials}

The datasets used and analyzed during the current study are available from the corresponding author on reasonable request.

\section{Declarations}

\section{Ethics approval and consent to participate}

The study was performed in accordance with the Declaration of Helsinki and approved by the ethical committee of Menoufiya Faculty of Medicine in December, 2015. Committee's reference number is not applicable. Written Informed consent was obtained from parents, and informed assent was obtained from the children before the collection of data. Data and headache diaries for patients were obtained from the patients or their parents

\section{Consent for publication}

Not applicable

\section{Competing interests}

The authors declare that they have no competing interests.

\section{Author details}

'Department of Neuropsychiatry, Faculty of Medicine, Menoufiya University, Shebin El-Kom 24211, Egypt. ${ }^{2}$ Department of Medical Biochemistry and Molecular Biology, Faculty of Medicine, Menoufiya University, Shebin El-Kom, Egypt.

Received: 6 February 2021 Accepted: 31 July 2021

Published online: 21 August 2021

\section{References}

1. Nakamura S, Morishita R, Moriguchi A, Yo Y, Nakamura Y, Hayashi S, et al. Hepatocyte growth factor as a potential index of complication in diabetes mellitus. J Hypertens. 1998;16:2019-26.

2. Zarnegar R, Michalopoulos G. Purification and biological characterization of human hepatopoietin a, a polypeptide growth factor for hepatocytes. Cancer Res. 1998:49:3314-20.
3. Liu Y, Wilkinson FL, Kirton JP. Hepatocyte growth factor and c-Met expression in pericytes: implications for atherosclerotic plaque development. J Pathol. 2007;212:12-9.

4. Kawamoto R, Oka Y, Yoshida O, Takagi Y. Significance of serum circulating hepatocyte growth factor in the development of carotid atherosclerosis. J Atheroscler Thromb. 2003;10:154-9.

5. Satani K, Konya H, Hamaguchi T, Umehara A, Katsuno T, Ishikawa T, et al. Clinical significance of circulating hepatocyte growth factor, a new risk marker of carotid atherosclerosis in patients with Type 2 diabetes. Diabetes UK Diabet Med. 2006;23:617-22.

6. Haug C, Schmid-Kotsas A, Zorn U, Bachem MG, Schuett S, Gruenertet $A$, et al. Hepatocyte growth factor is upregulated by low-density lipoproteins and inhibits endothelin-1 release. Am J Physiol Heart Circ Physiol. 2000;279:2865-71

7. Beilmann M, Vande Woude GF, Dienes HP, Schirmacher P. Hepatocyte growth factor-stimulated invasiveness of monocytes. Blood. 2000;95:3964-9.

8. Moulton K, Vakili K, Zurakowski D, Soliman M, Butterfield C, Sylvin E, et al. Inhibition of plaque neovascularization reduces macrophage accumulation and progression of advanced atherosclerosis. Proc Natl Acad Sci U S A. 2003;100:4736-41.

9. Munehisa S, Naoyuki S, Satoshi W. Gene transfer of hepatocyte growth factor gene improves learning and memory in the chronic stage of cerebral infarction. Hypertension. 2006;47:742-51.

10. Ozaki S, Beppu H, Sonoda S, Okazaki H, Mizutani K, Itani Y, et al. Relationship between cytokine concentration and activities of daily living in rehabilitation patients with stroke. Rinsho Byori. 2007:55:522-7.

11. Doeppner TR, Kaltwasser B, ElAli A, Zechariah A, Hermann DM, Bähr $M$. Acute hepatocyte growth factor treatment induces long-term neuroprotection and stroke recovery via mechanisms involving neural precursor cell proliferation and differentiation. J Cereb Blood Flow Metab. 2011;31:1251-62.

12. Yoshikuni Y, Katsuhiko K, Yasuharu T, Igase M, Nakura J, Miki T. Plasma hepatocyte growth factor and the relationship between risk factors and carotid atherosclerosis. Hypertens Res. 2002;25:661-7.

13. Yamamoto Y, Kohara K, Tabara Y, Igase M, Nakura J, Miki T. Association between carotid arterial remodeling and plasma concentration of circulating hepatocyte growth factor. J Hypertens. 2001;19:1975-9.

14. Duplyakov D, Emel'ianenko V, Goleva S, Svetlakova L, Sysuenkova E. Carotid artery intima-media thickness and severity of coronary atherosclerosis. Ter Arkh. 2003;76(11):14-7.

15. Shin T, Toshifumi M, Toshiyuki M, Kamide K, Tanaka T, Kokubo Y, et al. Identification of 21 single nucleotide polymorphisms in human hepatocyte growth factor gene and association with blood pressure and carotid atherosclerosis in the Japanese population. Atherosclerosis. 2004;173:301-7.

16. Akaihata H, Takahashi N, Nakajima T, Oguro T, Sagawa K, Kumagai K, et al. Voiding Symptoms And Storage Symptoms In Male Patients With Luts; Which Symptoms Are Aggravated By Atherosclerosis. International continence society (ICS), Poster, Beijing, china, 2012, 42nd Annual meeting, October 15-19, 437

17. Rozeman AD, Hund H, Westein M, Wermer M, Lycklama Gj, Boiten J, et al. Duplex ultrasonography for the detection of vertebral artery stenosis A comparison with CT angiography. Brain Behav. 2017;7(8):00750.

18. Matsumori A, Furukawa Y, Hashimoto T, Ono K, Shioi T, Okada M, et al. Increased circulating hepatocyte growth factor in the early stage of acute myocardial infarction. Biochem Biophys Res Commun. 1996:221:391-5

19. Matsumori A, Takano H, Obata JE, Takeda S, Tsuyuguchi N, Ono K, et al. Circulating hepatocyte growth factor as a diagnostic marker of thrombus formation in patients with cerebral infarction. Circ J. 2002;66:216-8.

20. Rajpathak SN, Wang T, Wassertheil-Smoller S, Strickler H, Kaplan RC, McGinn A, et al. Hepatocyte growth factor and the risk of ischemic stroke developing among postmenopausal women: results from the women's health initiative. Stroke. 2010;41:857-62.

21. Anan F, Shimomura T, Imagawa M, Masaki T, Nawata T, Takahashi N, et al. Predictors for silent cerebral infarction in patients with chronic renal failure undergoing hemodialysis. Metabolism. 2007;56:593-8.

22. Bell EJ, Larson NB, Decker PA, Pankow JS, Tsai MY, Hanson NQ, et al. Hepatocyte growth factor is positively associated with risk of stroke. Stroke. 2016:47(11):2689-94. 
23. Rina N, Satoshi K, Tatsuya I. Increased expression of hepatocyte growth factor in cerebrospinal fluid and intracranial artery in moyamoya disease. Stroke. 2004;35:2837-42.

24. Chowdhury M, Ghosh J, Slevin M, Smyth JV, Alexander MY, SerracinoInglott F. A comparative study of carotid atherosclerotic plaque microvessel density and angiogenic growth factor expression in symptomatic versus asymptomatic patients. Eur J Vasc Endovasc Surg. 2010;39:388-95.

25. Ma H, Calderon TM, Fallon JT, Berman JW. Hepatocyte growth factor is a survival factor for endothelial cells and is expressed in human atherosclerotic plaques. Atherosclerosis. 2002;164:79-87.

26. McKinnon H, Gherardi E, Reidy M, Bowyer D. Hepatocyte growth factor/ scatter factor and MET are involved in arterial repair and atherogenesis. Am J Pathol. 2006;168:340-8.

27. Steinbrook R. The price of sight—ranibizumab, bevacizumab, and the treatment of macular degeneration. N Engl J Med. 2006;355:1409-12.

28. Nagayama T, Nagayama M, Kohara S, Kamiguchi H, Shibuya M, Katoh $Y$, et al. Post-ischemic delayed expression of hepatocyte growth factor and c-Met in mouse brain following focal cerebral ischemia. Brain Res. 2004;999:155-66.

29. Shimamura M, Sato N, Waguri S, Uchiyama Y, Hayashi T, lida H, et al. Gene transfer of hepatocyte growth factor gene improves learning and memory in the chronic stage of cerebral infarction. Hypertension. 2006:47:742-51.

30. Zhu Z, Xu T, Guo D, Huangfu X, Zhong C, Yang J, et al. Serum hepatocyte growth factor is probably associated with 3-month prognosis of acute ischemic stroke. Stroke. 2018;49:377-83.
31. Wang W, Li M, Chen Q, Wang J. Hemorrhagic transformation after tissue plasminogen activator reperfusion therapy for ischemic stroke: mechanisms, models, and biomarkers. Mol Neurobiol. 2015;52:1572-9.

32. Zhao H, Li F, Huang Y, Zhang S, Li L, Yang Z, et al. The incremental prognostic value of sIL-2R and HGF in acute ischemic stroke. Res Square. 2020 https://doi.org/10.21203/rs.2.21269/v2.

33. Date I, Takagi N, Takagi K, Kago T, Matsumoto K, Nakamura T, et al. Hepatocyte growth factor improved learning and memory dysfunction of microsphere embolized rats. J Neurosci Res. 2004;78:442-53.

34. Wen Z, Rong J, Meng M. Therapeutic potential of hepatocyte growth factor against cerebral ischemia (Review). Exp Ther Med. 2014;9:283-8.

35. Kitamura K, Fujiyoshi K, Yamane J-i, Toyota F, Hikishima K, Nomura T, et al. Human hepatocyte growth factor promotes functional recovery in primates after spinal cord injury. PLoS ONE. 2011;6(11):27706.

36. Takano M, Kawabata S, Shibata S, Yasuda A, Nori S, Tsuji O, et al. Enhanced functional recovery from spinal cord injury in aged mice after stem cell transplantation through HGF induction. Stem Cell Rep. 2017;8:509-18.

37. Boldyreva MA, Bondarb V, Stafeevac S, Makarevich PI, Beloglazova IB, Zubkova ES, et al. Plasmid-based gene therapy with hepatocyte growth factor stimulates peripheral nerve regeneration after traumatic injury. Biomed Pharmacother. 2018;101:682-90.

\section{Publisher's Note}

Springer Nature remains neutral with regard to jurisdictional claims in published maps and institutional affiliations.

\section{Submit your manuscript to a SpringerOpen ${ }^{\circ}$ journal and benefit from:}

- Convenient online submission

- Rigorous peer review

- Open access: articles freely available online

- High visibility within the field

- Retaining the copyright to your article

Submit your next manuscript at $\boldsymbol{\nabla}$ springeropen.com 